\title{
NATIONAL CULTURE DIMENSION OF POWER DISTANCE IN THE BALTIC STATES
}

\author{
Stanislava Luptáková, Branislav Vargic, Ivan Kincel \\ Comenius University, Faculty of Management \\ Odbojárov 10P.O.BOX 95,820 05 BRATISLAVA 25, Bratislava, Slovakia
}

Received:03 03 2005, accepted 02052005

\begin{abstract}
The paper presents a calculation for the values of power distance index in the countries of Latvia, Lithuania and Estonia using a mathematical model that is based on the correlations between power distance index values of the original research conducted by Geert Hofstede and macroeconomic indicators. Following, the paper presents implications of the found power distance indexes on managerial practices in the local organizations as well as on transferability of the managerial practices of multinationals presented in the region onto the local workforce.
\end{abstract}

Keywords: power distance index, macroeconomic indicators, human resource.

\section{Introduction}

Science of social anthropology has developed a theory that all societies - in today's world mostly represented by individual nations or geographically grouped countries - face basic problems of high similarity: a) relation to authority, b) the relationship between individual and society, c) the individual's concept of masculinity and femininity and d) ways of dealing with conflicts, including control of aggression and the expression of feelings [1].

These problems, as identified by Inkeles and Levinson, became the theoretical base of a research project that has, over the last 30 years, established itself as one of the most important studies attempting to depict the impact of culture differences on various aspects of society, including the workplace. The research project was conducted by a Dutch researcher Geert Hofstede, who performed an employee opinion survey involving 116,000 IBM employees in 40 different countries, asking people for their preferences in terms of management style and work environment. A statistical analysis of the answers on questions about the values of IBM employees in different countries revealed common problems which were very similar to the aforementioned issues identified by social anthropologists, and showed how solutions to these problems differ from country to country in the following areas: 1) social inequality, including the relationship with authority; 2) the relationship between the individual and the group; 3) concepts of masculinity and femininity, the social implications having been born as a boy or a girl; 4) ways of dealing with uncertainty, relating to the control of aggression and the expression of emotions [2].

The four basic problem areas defined by Inkeles and Levinson and empirically found by Hofstede represent the dimensions of culture, named consequently as collectivism versus individualism, femininity versus masculinity and uncertainty avoidance and power distance. More recently, a fifth dimension of differences among the national cultures was identified, contrasting a long term orientation in life to short term orientation [3]. For the purpose of this article, the dimension of power distance will be hereafter focused on. 


\section{Power distance index}

Generally speaking, power distance provides answers (in organizational setting) to questions of the following nature: To what extent do employees acknowledge that their boss has more power than they have? Is the boss right because he or she is the boss or are the bosses correct in their decisions because they have the knowledge to provide the right answer? Do the employees perform the task because their boss wants them to do it that way or because they believe it is the best way to do it?

Power distance index (PDI), as defined by Hofstede [2], reflects the range of following answers in his original survey to questions of how to handle the fact that people are unequal:

1. Answers by employees to the question: How frequently in your experience does the following problem occur: employees being afraid to express disagreement with their managers? (mean score on 1 -5 scale from very frequently to very seldom).

2. Subordinates' perception of their boss's actual decision making style (percentage choosing either the description of an autocratic or of a paternalistic style, out of possible four styles plus a 'none of these' alternative).

3. Subordinates' preference for their boss's decisionmaking style (percentage preferring an autocratic or paternalistic style, or, on the contrary, a style based on majority vote, but not a consultative style) [2].

Thus, the responses to questions (1) and (2) indicate the way the respondents perceive their daily work environment, answer to question (3) indicates what the respondents express as their preference or how they would like their work environment to be. The score indicating the power distance index (and thus the placement of a country on a power distance list) was then computed from the mean score of the answers to these three questions.

As a result of the calculations, power distance indexes were composed and a list of countries ranked from the highest power distance index to the one with a lowest power distance index was created (Table 1).

Following these results, Hofstede defines power distance as ,the extend to which the less powerful members of institutions and organizations within a country expect and accept that power is distributed unequally"[2]. For Hofstede, institutions are the basic elements of society like the family, school or the community and organizations are places of work. The implications of the power distance dimension are numerous. Hofstede discusses the insinuations for schools (the teacher student relationship), for a family (the parent - child relationship) or even for a state (the authority - citizen relationship). For the purpose of this article, however, the focus is placed on those implications of power distance concerning the work place.

\section{Power distance at the workplace}

In low power distance countries, according to [2], there is limited dependence of subordinates on their superiors, preference for consultation, and an understanding of mutual equality between a superior and subordinate. Additionally, the emotional distance between a subordinate and superior is relatively small; as a result subordinates will quite readily approach and contradict their bosses. As Hofstede explains, in countries where employees are not seen as very afraid and bosses as not often autocratic or paternalistic, employees express preference for a consultative style of decision making; a boss who usually consults with his/her subordinates before reaching a decision [4].

Moreover, organizations are fairly decentralized, with flat hierarchical pyramids and limited numbers of supervisory personnel. Salary ranges between top and bottom jobs are relatively small, workers are highly qualified and high-skill manual labor has a higher status than low1 - skill office work. Superiors should be accessible for subordinates and the ideal boss is a resourceful democrat. On the other hand, subordinates expect to be consulted before a decision is made that effects their work [5].

In countries on the opposite side of the power distance scale, employees are seen as frequently afraid of disagreeing with their bosses and bosses as autocratic or paternalistic [2]. Moreover, employees in similar jobs are less likely to prefer a consultative boss; instead many among them express a preference for a boss who decides autocratically or paternalistically. In fact, as Adler states: ,....authoritative decision making and leadership style may work the best in these countries"[6]. In large power distance countries the relationship between boss and subordinate is strictly ruled and dependent on the decisions of the superior. Additionally, in companies with larger power distance there is a very centralized organization; subordinates expect to be told what to do from their superiors because they consider each other as unequal. Inequalities are normally expected and superiors see privileges as desirable. Furthermore, people in large power distance cultures express positive emotions to superiors and negative emotions to subordinates. 
Table 1. Hofstede's power distance index list (www.geert-hofstede.com, retrieved May 3, 2004)

\begin{tabular}{|c|c|c|c|}
\hline Country & PDI & Country & PDI \\
\hline Malaysia & 104 & Iran & 58 \\
\hline Guatemala & 95 & Taiwan & 58 \\
\hline Panama & 95 & Spain & 57 \\
\hline Philippines & 94 & Pakistan & 55 \\
\hline Mexico & 81 & Poland & 55 \\
\hline Venezuela & 81 & Japan & 54 \\
\hline Arab World & 80 & Italy & 50 \\
\hline China & 80 & Argentina & 49 \\
\hline Ecuador & 78 & South Africa & 49 \\
\hline Indonesia & 78 & Hungary & 45 \\
\hline India & 77 & Jamaica & 45 \\
\hline West Africa & 77 & United States & 40 \\
\hline Singapore & 74 & Canada & 39 \\
\hline Brazil & 69 & Netherlands & 38 \\
\hline France & 68 & Australia & 36 \\
\hline Hong Kong & 68 & Costa Rica & 35 \\
\hline Colombia & 67 & Czech Republic & 35 \\
\hline EI Salvador & 66 & Germany & 35 \\
\hline Turkey & 66 & United Kingdom & 35 \\
\hline Belgium & 65 & Switzerland & 34 \\
\hline East Africa & 64 & Finland & 33 \\
\hline Peru & 64 & Norway & 31 \\
\hline Thailand & 64 & Sweden & 31 \\
\hline Chile & 63 & Ireland & 28 \\
\hline Portugal & 63 & New Zealand & 22 \\
\hline Uruguay & 61 & Denmark & 18 \\
\hline Greece & 60 & Israel & 13 \\
\hline South Korea & 60 & Austria & 11 \\
\hline
\end{tabular}

Superiors and subordinates deem bypassing to be insubordination (in low power distance countries, employees circumvent the boss frequently in order to get the work done).

\section{Power distance and human resource management practices}

Based on the characteristics of small and large power distance relationships mentioned above, one can argue, that power distance influences structural variables, such the amount of formal hierarchy and the degree of centralization. As for managerial practices, one can assume, based on previous findings, that the cultural assumptions about the level of hierarchy and positional authority within organizations influence the amount of participation in decision-making, managerial style along with the established communication patterns and the communication style preferred. Moreover, one can argue that the influences play important role in managerial decisions on „format" of human resource management practices and activities in organizations, such as performance appraisal, compensation models or selection procedures [7].

A countless number of research findings show, that nearly the whole spectrum of human resource management (HRM) practices are to a greater or lesser extent influenced by national cultures dimensions, as defined by Hofstede. As Sparrow and Wu remark: „,...high number of individual HRM policies and practices preferences is significantly linked and predictable from national culture value orientations" [8].

For example, decisions on training programs can reveal cultural assumptions of individualism versus collectivism (whether the training needs are determined by individuals or by the organization) or uncertainty avoidance (whether to use case study approach or lecture approach as a training method) [9; 10]. Furthermore, as Schuler and Rogovsky [11] claim, 
decisions on compensation system could unveil masculinity versus femininity assumption (extent of preference of financial rewards over non-financial) or uncertainty avoidance (what proportion of salary is fixed and variable).

Power distance in particular plays an important role in a specific area of HRM, that of performance assessment. Chow and his colleagues found that employees' power distance significantly affects their reactions to different modes of implementing performance standards. They report, that employees from lower power distance societies expect to be included in performance appraisal session, whereas employees from higher power distance cultural setting take for granted the fact, that it is their superior who has the full responsibility for appraisal process. In support of these arguments, Ramamoorthy and Carroll argued that „formal appraisal systems point to high individualism and high power distance cultures whereas collectivist and lower power distance cultures emphasize more informal appraisal systems“".

Another important aspect of the appraisal process, reflecting power distance, is the choice of appraiser. Appraisals performed by immediate supervisors indicate a top - down orientation within organizations and a potential preference for hierarchical structures. In multi-source assessment systems (360 degree feedback) appraisees are rated by a variety of other employees including supervisors, subordinates, peers and external stakeholders, such as customers. This form of appraisal suggests an organizational preference to increased employee participation and empowerment [12].

If superiors and subordinates are expected to engage in a two-way dialogue (as a performance assessment tool) to agree on what has to be done, when and how, one can argue, that this exposes the cultural assumption of low power distance. In practice, this relates to problems of transferring management by objectives (MBO) - as a PA technique - to some cultures, as reported by various researchers $[4,13,14]$.

A different aspect of power distance in relation to performance assessment can be seen in multinational companies. As Kovach states: „when applying performance appraisal across subsidiaries of a multinational company, it can be affected by the culture in which it originated (the home country of headquarters), or by the cultural background of the ratee (in case of expatriates giving feedback to locals) “ [15]. This notion is supported by Groeschl [12], who argues, that in the process of choosing the appropriate method of performance appraisal, the choice varies in the degree of participation and openness according to organizational culture as well as national culture. Organizations choosing methods which encourage appraisees to participate in the process of appraisal and its outcomes, as Groeschl adds, are more participative and supportive in the overall management style and thus point to less hierarchical orientation (resembling Hofstede's power distance). Organizations which are less open, could give the impression of being rather authoritative in their overall management style [12].

The notion presented by Kovach and supported by Groeschl presents important finding in relation to the topic of this article. From the perspective of HRM practices in multinational companies, research has found that of all management functions human resource management tends to adhere most closely to local practices in multinational companies. $[16,17,18]$ suggest there are two explanations for this: 1) HRM practices are strongly locally governed by the legal boundaries that set the "limits" for the employeremployee relationships on the formal level; 2) subsidiaries of multinational companies often have no other choice than to hire the local labour and thus it is difficult for them to diverge from the local managerial practices strongly guided by the values and views on managerial practice common in the local national culture.[2] contributes to this debate as well, by stating that organizations headquartered in larger power distance cultures have more problems functioning in smaller power distance cultures.

The findings mentioned above show that decision of a multinational company on where to establish its foreign subsidiary may be dependent on cultural proximity of the country of subsidiary. In other words, the resemblance of national culture value (for example power distance) between the country of the mother company and the planned country of establishing the subsidiary plays a certain role in the decisions of multinationals for international expansion. Of course, one has to be aware that other factors, such as stability of economic and political environment, mode of entry or education level of the local workforce play role in these decisions as well.

\section{Need to study power distance in $\mathbf{E U}$ accession countries}

For obvious historical reasons, none of the new EU accession countries (except former Yugoslavia) were originally included in Hofstede's work [4]. Throughout the nineties, however, the Czech Republic, Poland and Hungary have been added to its later revisions. More over, limited number of other scholars has contributed 
to the debate over the cultural characteristics of the EU accession countries. Recent developments in these countries and especially the ever growing presence of multinational companies create a need for further examination of national culture aspects of these countries, including power distance. One could argue, that since subsidiaries of multinational companies rely heavily on the local work force, one of the major challenges they face in this region is the challenge of understanding the beliefs, behaviors, attitudes and aptitudes of the local workforce. In order to cope with this challenge, their understanding of the local (national) culture represents a crucial element determining their success or failure in the region. Additionally, understanding of the local influences their decisions on appropriateness of particular HRM practices.

\section{Calculation of power distance using macroeconomic indicators}

In the previous work, authors of this article introduced the methodology to calculate the power distance index valid for any given country [19]. In summary, it is based on Hofstede, who claims that:

„...the country's PDI score can be fairly accurately predicted from the country's geographical latitude (higher latitude associated with lower PDI), its population size (larger size associated with higher PDI) and its wealth (richer countries associated with lower PDI). latitude, population size and per capita gross national product predict 58 per cent (of the variance in PDI). If one knew nothing else about these countries other than those three hard to fairly hard data one would be able to make a list of predicted PDIs."

For the analysis, the authors have used Hofstede's ranking of states (see Table 1) and assigned each country (excluding the regions and non-existing countries) the macroeconomic data that Hofstede finds correlating with power distance: size of the country, its geographic location, and wealth of the country. However, as Hofstede does not specify exactly what type of macroeconomic data he finds correlated to the power distance index, the authors have analyzed various indicators and came to the conclusion that for the purpose of this study they would use the following:

1. size of population as indicator of country's size;

2. geographic location of the capital city of the country;

3. GDP per capita in the year 2000 as an indicator of the wealth of the country.

For the purpose of including a specific country on PDI chart there is a need to express PDI as a function of the three variables mentioned above. To obtain this function, a mathematical method of linear regression was used. The crucial part of this method is the decision regarding how the measured data should be approximated. This decision is usually made rather freely and by estimate. In this case, an estimate based on previous experience is hardly possible. However, the relationship between latitude and PDI (definite value of PDI on the equator and monotonous decline of PDI towards increasing latitude) suggests exponential dependence of PDI on latitude.

The results of this approximation are not convincing enough. Although they copy the extreme values of PDI well, inside the interval of set of values the estimates are significantly different from the measured values. The estimates through goniometric and logarithmic functions show similar results. Therefore, it was decided to make estimates by a polynomial function.

The decision for polynomial was based on a wellproven ability of polynomials to extrapolate any set of values given. Using a polynomial of sufficiently high degree would match the original values with any precision desired, but intervals on which the function is monotonous tend to be even shorter and value difference between boundary values bigger (the graph includes more and steeper ,hills“ on the same interval) with rising degree. This would have impact on predicting functional value in any new point. Consequently, to obtain a useful prediction, highdegree polynomials should be avoided. Therefore (and to keep the model as simple as possible) it was decided to use a first-degree polynomial function of type

$f(x, y, z)=a_{1} x+a_{2} y+a_{3} z+a_{4} x y+a_{5} x z+a_{6} y z+$ $a_{7} x y z+a_{0}$,

where

$$
\begin{aligned}
& \mathrm{x}, \mathrm{y}, \mathrm{z}-\text { our three variables, } \\
& \mathrm{a}_{0}, \mathrm{a}_{1}, \ldots, \mathrm{a}_{7}-\text { parameters. }
\end{aligned}
$$

We did not include any terms of $1 / x$ or similar, because they make the function acquire very large values in points close to zero or even infinite value in zero, which is completely unacceptable in case of latitude and very doubtful in other used variables. Finally, we have obtained parameters in our function. Then we have entered data for a specific country into the function (with previously calculated parameters) and obtained results as can be seen in Table 2. Following we have elaborated a complete table of power distance indexes, as presented in Table 3 (including the variables and the calculated values for the Baltic states). 
Table 2. Power distance values for the Baltic states

\begin{tabular}{ccc}
\hline Country & Estimated PDI & Rounded to integer \\
\hline Estonia & 46,6676 & 47 \\
Latvia & 51,6171 & 52 \\
Lithuania & 52,3829 & 52 \\
\hline
\end{tabular}

Table 3. Geographical and macroeconomic data and estimated values of power distance

\begin{tabular}{|c|c|c|c|c|c|c|c|}
\hline $\begin{array}{l}\text { Hofstede's } \\
\text { Rank }\end{array}$ & Country & $\begin{array}{l}\text { Hofstede's } \\
\text { PDI } \\
\text { Score }\end{array}$ & $\begin{array}{l}\text { Population } \\
\text { Size }^{*} \\
2001\end{array}$ & $\begin{array}{c}\text { Capital } \\
\text { city }\end{array}$ & $\begin{array}{c}\text { Geographical } \\
\text { latitude } \\
\text { of the capital city }\end{array}$ & $\begin{array}{c}\text { GDP per } \\
\text { capita } 2000 \\
\text { (USD) }\end{array}$ & $\begin{array}{c}\text { Estimated } \\
\text { PDI }\end{array}$ \\
\hline 1 & Malaysia & 104 & $22,229,040$ & Kuala Lumpur & $3 \mathrm{n} 10,101 \mathrm{e} 42$ & 10300 & 75,0776 \\
\hline $2 / 3$ & Guatemala & 95 & $12,974,361$ & Guatemala & $14 n 38,90 w 31$ & 3700 & 72,2133 \\
\hline $2 / 3$ & Panama & 95 & $2,845,647$ & Panama & $8 \mathrm{n} 58,79 \mathrm{w} 32$ & 6000 & 73,0557 \\
\hline 4 & Philippines & 94 & $82,841,518$ & Manila & $14 \mathrm{n} 35,121 \mathrm{e} 0$ & 3800 & 73,4321 \\
\hline $5 / 6$ & Mexico & 81 & $101,879,171$ & Mexico & 19n24, 99w09 & 9100 & 68,072 \\
\hline $5 / 6$ & Venezuela & 81 & 23,916,810 & Caracas & $10 \mathrm{n30}, 66 \mathrm{w} 56$ & 6200 & 73,0451 \\
\hline 7 & Arab Countries & 80 & - & - & - & - & \\
\hline $8 / 9$ & Ecuador & 78 & $13,183,978$ & Quito & $0 s 13,78 w 30$ & 2900 & 78,0934 \\
\hline $8 / 9$ & Indonesia & 78 & $228,437,870$ & Jakarta & $6 \mathrm{~s} 10,106 \mathrm{e} 48$ & 2900 & 81,3806 \\
\hline $10 / 11$ & India & 77 & $1,029,991,14$ & New Delhi & $28 \mathrm{n} 36,77 \mathrm{e} 12$ & 2200 & 77,4875 \\
\hline $10 / 11$ & West Africa & 77 & - & - & - & - & \\
\hline 12 & Yugoslavia & 76 & - & - & - & - & \\
\hline 13 & Singapore & 74 & $4,300,419$ & Singapore & $\ln 16,103 \mathrm{e} 51$ & 26500 & 73,0066 \\
\hline 14 & Brazil & 69 & $174,468,575$ & Brasilia & $15 \mathrm{~s} 46,47 w 55$ & 6500 & 72,3441 \\
\hline $15 / 16$ & France & 68 & $59,551,227$ & Paris & $48 \mathrm{n} 52,2 \mathrm{e} 20$ & 24400 & 39,3586 \\
\hline $15 / 16$ & Hong Kong & 68 & $7,210,505$ & & $22 \mathrm{n} 17,114 \mathrm{e} 09$ & 25400 & 56,4752 \\
\hline 17 & Colombia & 67 & $40,349,388$ & Bogota & 4n36, 74w05 & 6200 & 75,9094 \\
\hline $18 / 19$ & El Salvador & 66 & $6,237,662$ & San Salvador & 13n42, 89w12 & 4000 & 72,3309 \\
\hline $18 / 19$ & Turkey & 66 & $66,493,970$ & Ankara & $39 \mathrm{n} 56,32 \mathrm{e} 52$ & 6800 & 59,7844 \\
\hline 20 & Belgium & 65 & $10,258,762$ & Brussels & $50 \mathrm{n} 50,4 \mathrm{e} 20$ & 25300 & 34,2687 \\
\hline $21 / 23$ & East Africa & 64 & - & - & - & - & \\
\hline $21 / 23$ & Peru & 64 & $27,483,864$ & Lima & $12 \mathrm{~s} 03,77 \mathrm{w} 03$ & 4550 & 73,1421 \\
\hline $21 / 23$ & Thailand & 64 & $61,797,751$ & Bangkok & $13 \mathrm{n} 45,100 \mathrm{e} 31$ & 6700 & 71,8242 \\
\hline $24 / 25$ & Chile & 63 & $15,328,467$ & Santiago & $33 \mathrm{~s} 27,70 w 40$ & 10100 & 59,7746 \\
\hline $24 / 25$ & Portugal & 63 & $10,066,253$ & Lisbon & $38 \mathrm{n} 43,9 \mathrm{w} 08$ & 15800 & 52,0408 \\
\hline 26 & Uruguay & 61 & $3,360,105$ & Montevideo & $34 \mathrm{~s} 53,56 w 11$ & 9300 & 59,5769 \\
\hline $27 / 28$ & Greece & 60 & $10,623,835$ & Athens & $37 \mathrm{n} 58,23 \mathrm{e} 43$ & 17,200 & 51,2988 \\
\hline $27 / 28$ & South Korea & 60 & $47,904,370$ & Seoul & $37 \mathrm{n33}, 126 \mathrm{e} 58$ & 16,100 & 53,1651 \\
\hline $29 / 30$ & Iran & 58 & $66,128,965$ & Tehran & $35 \mathrm{n} 40,51 \mathrm{e} 26$ & 6,300 & 62,1314 \\
\hline $29 / 30$ & Taiwan & 58 & $22,370,461$ & Taipei & $25 \mathrm{n} 03,121 \mathrm{e} 31$ & 17,400 & 59,3976 \\
\hline 31 & Spain & 57 & $40,037,995$ & Madrid & $40 \mathrm{n} 24,3 \mathrm{w} 41$ & 18,000 & 49,7293 \\
\hline 32 & Pakistan & 55 & $144,616,639$ & Islamabad & $33 \mathrm{n} 42,73 \mathrm{e} 10$ & 2,000 & 66,6911 \\
\hline \multirow[t]{3}{*}{33} & Japan & 54 & $126,771,662$ & Tokyo & $35 \mathrm{n} 42,139 \mathrm{e} 46$ & 24,900 & 49,083 \\
\hline & LATVIA & 52 & $2,375,300$ & Riga & $56 \mathrm{n} 57,24 \mathrm{e} 06$ & 6,904 & 51,6171 \\
\hline & LITHUANIA & 52 & $3,466,600$ & Vilnius & $54 \mathrm{n} 00,24 \mathrm{e} 30$ & 7,104 & 52,3829 \\
\hline 34 & Italy & 50 & $57,679,825$ & Rome & $41 \mathrm{n} 54,12 \mathrm{e} 29$ & 22,100 & 45,779 \\
\hline $35 / 36$ & Argentina & 49 & $37,384,816$ & Buenos Aires & $34 \mathrm{~s} 36,58 \mathrm{w} 27$ & 12,900 & 57,217 \\
\hline \multirow[t]{2}{*}{$35 / 36$} & South Africa & 49 & - & - & - & - & \\
\hline & ESTONIA & 47 & $1,372,071$ & Tallin & $59 \mathrm{n} 00,22 \mathrm{e} 00$ & $\mathbf{9 , 8 8 9}$ & 46,6676 \\
\hline 37 & Jamaica & 45 & $2,665,636$ & Kingston & $18 \mathrm{n} 0,76 \mathrm{w} 48$ & 3,700 & 70,7155 \\
\hline 38 & USA & 40 & 278,058,881 & Washington, DC & $38 \mathrm{n} 54,77 \mathrm{w02}$ & 36,200 & 46,131 \\
\hline 39 & Canada & 39 & $31,592,805$ & Ottawa & $45 \mathrm{n} 25,75 \mathrm{w} 42$ & 24,800 & 39,9644 \\
\hline 40 & Netherlands & 38 & $15,981,472$ & Amsterdam & $52 \mathrm{n} 22,4 \mathrm{e} 54$ & 24,400 & 34,4313 \\
\hline 41 & Australia & 36 & $19,357,594$ & Canberra & $35 \mathrm{~s} 17,149 \mathrm{e} 08$ & 23,200 & 48,2848 \\
\hline $42 / 44$ & Costa Rica & 35 & 3,773,057 & San Jose & 9n56, 84w05 & 6,700 & 72,8404 \\
\hline $42 / 44$ & Germany (West) & 35 & $83,029,536$ & Berlin & $52 \mathrm{n} 30,13 \mathrm{e} 22$ & 23,400 & 39,3222 \\
\hline $42 / 44$ & United & 35 & $59,647,790$ & London & $51 n 30,0 w 10$ & 22,800 & 39,178 \\
\hline 45 & Switzerland & 34 & $7,283,274$ & Bern & $46 \mathrm{n} 57,7 \mathrm{e} 26$ & 28,600 & 33,7388 \\
\hline 46 & Finland & 33 & $5,175,783$ & Helsinki & $60 \mathrm{n} 10,24 \mathrm{e} 58$ & 22,900 & 29,6543 \\
\hline
\end{tabular}

* Density was calculated as the population size divided by the size of the country in $\mathrm{km} 2$ 
If we take a closer look at the table containing the original values as well as our estimates, we can see the estimates on both extremes are only for orientation, but in the middle part of the original table, our estimates are quite precise. There are a few exceptions; however, these are of low significance, since we are not dealing with exact functional values, but with 58 per cent correlation.

The weakness of the chosen type of function is that it decreases in reliability in predicting values when approaching the sides of original interval and proceeding beyond. But otherwise the chosen type of function gives a pretty fair estimate of whether the PDI value is to be expected high or low. A good example that the function does not work well in extreme values of variables, especially latitude, is Costa Rica, latitude of which causes it to acquire much higher estimate than the original value found.

Another important noteworthy fact when discussing difference between the original list and our ranking is that the original Hofstede's research data are more than 20 years old, and we have used recent values for population and GDP per capita. This also could have impact on our estimates, though if we consider culture as changing and evolving very slowly in time, this has rather insignificant influence.

\section{Discussion and implications}

The presented paper argues that the values of power distance index for the three countries of the Baltic region - Lithuania, Latvia and Estonia - are quite similar. The calculated value for Lithuania is „,52“, Latvia is ,52"and Estonia has the PDI value of „,47“. Power distance index values around ,50"indicate that the subordinates need to receive regular feedback on their performance and simultaneously they are willing to defend their own standpoints. Thus managers can benefit from engaging the subordinates in decisionmaking, particularly the joint planning of their future goals and performance standards.

There are two main implications of the understanding of the power distance index values within a certain cultural setting:

1. implications for management practices used in a given country and the rationale for their usage

2. implications for multinational companies that desire to standardize their management policies and need to understand the degree of acceptance of the introduced policies within the new, host cultural setting

\section{Implications for management practices used in a given country}

Generally speaking, all of the values are around ,50“, which is in the middle of the PDI scale. This implies that the style of management and managerial practices that involve communication between the supervisor/ manager and the subordinate can be open and flexible. However the managers would require the formal recognition of their status. While respect for the managers and a certain degree of distance is everpresent even in the countries with the lowest values of PDI, the formalization of the relationship between the supervisor and the subordinate become more evident with increasing values of PDI.

Performance management and assessment of subordinates are the most dominant practices among those that involve active communication between managers and their subordinates. Providing a balanced feedback to the employees is a crucial step in achieving a consistent system of training, career development and compensation. Power distance reflects the degree to which employees are willing and comfortable when engaging in a discussion about their goals and evaluation of their past performance and performance-related behavior. Management by objectives can be a feasible tool to motivate the employees.

\section{Implications for multinational companies}

The degree to which any given management practice or policy will be accepted in a new cultural environment depends on the proximity of the culture of origin, or home country culture, of the multinational corporation with the culture of the host country. When a foreign company enters into a new culture and it is a culturally similar country, the implementation of management practices as well as the acceptance of the individual managerial style of a particular manager will be faster and easier.

The compatibility of the power distance index values is especially crucial as it reflects most aspects of management policies and most aspects of managerial style of people.

In the area of management policies, power distance index is reflected in performance appraisal, the level of link between performance and career advancement, performance and compensation (performance driven pay) and performance and training. In the area of individual managerial style, power distance index is reflected in the way managers assign goals, how they 
expect their subordinates to participate in discussions and in the process of decision-making, to what degree they empower and trust their employees and how they provide feedback to them.

When we examined the volumes of foreign direct investment into the Baltic region, we see a dominance of Scandinavian countries followed by Germany and the USA. For example, in case of Lithuania, Denmark has the strongest position, followed by Sweden, Germany, Finland and the USA ${ }^{1}$. Our estimate for the power distance value of Sweden is „31.4“, for Germany the value is „39.3“, Finland has the value of „30" and the USA has the value of „46" which is closest power distance value to the values of the Baltic countries. The values of Sweden, Finland and Germany are more distant from the values of Lithuania, Latvia and Estonia. This suggests that the managerial practices that these countries implement will need to be tailored to the needs and customs of the local population.

Thus we suggest that when the companies enter a cultural setting that is culturally more distant, they might consider choosing a person from a third country for a position of the expatriate manager, provided the third country is culturally closer. A personal managerial style can serve as a filter to speed up the acceptance of policies and practices that might otherwise be considered too strange and the company fears facing resistance in the new host country.

\section{Research implications}

The presented paper calculates the values of power distance index using a mathematical model that is based on the correlations between power distance index values of the original research conducted by Geert Hofstede and macroeconomic indicators. The anecdotal evidence as well as our personal experience in the examined countries support the calculated values, however, for more comprehensive understanding of the power distance within the cultural setting of Lithuania, Latvia and Estonia, a more in depth research is needed. A study that would examine particular management practices related to power distance should be carried out, either on an individual country basis or as a comparable study among the three countries.

\footnotetext{
${ }^{1}$ Foreign direct investment by investing country (as of January 1) retrieved on April 8th, 2005 from http://www.std.lt/web/ main.php?parent $=707$
}

\section{Conclusions}

The authors of the presented paper have examined one dimension of national culture - power distance as defined by Hofstede. Using a mathematical model, we defined the degree of power distance and the specific values of power distance index for the countries of the Baltic region. The calculated values are as follows:

\section{Lithuania 52 \\ Latvia 52 \\ Estonia 47}

The understanding of the power distance index can help the process of implementation of managerial practices that are proven successful in a different environment. Practices from a country with similar values will be more readily acceptable than those that are further away on the power distance index scale. In case of Lithuania, Latvia and Estonia, the countries that have power distance values close to the value of „50“ will be culturally closer and their management practices will be more feasible with the local attitudes and practices. The same conclusions can be drawn for the style of management and interpersonal communication of individual managers travelling and working abroad.

\section{References}

1. Inkeles A. and Levinson D. J. (1969). National character: the study of modal personality and sociocultural systems. In: Hofstede G. (1997). Cultures and Organizations - Software of the mind. New York. McGraw Hill.

2. Hofstede G. (1997). Cultures and Organizations: Software of the mind. New York. Mc - Graw Hill.

3. Hofstede G. and Bond M. H. (1988). The Confucius connection: from cultural roots to economic growth. Organizational Dynamics, Vol. 16, No. 4, p. 4-21.

4. Hofstede G. (1980). Culture's consequences: International differences in work related values. Beverly Hills. Sage publications.

5. Hofstede G. (1993). Cultural constraints in management theories. Academy of Management Executive, Vol. 7, No. 1, p. 81-93.

6. Adler N. (1997). International Dimensions of Organizational Behavior. Cincinnati. South Western College Publishing

7. Baskerville R. F. (2003). Hofstede never studied culture. Accounting, Organizations and Society, Vol. 28, p. 114.

8. Sparrow P. and Wu P. C. (1998). Does national culture really matter? Predicting HRM preferences of Taiwanese employees. Employee Relations, Vol. 20, Iss 1, p. 26. 
9. Stewart R.; Barsoux J. L.; Kieser A.; Ganter D. and Walgenbach P. (1994). Managing in Britain and Germany. London. Macmillan In: Schneider S. C. and Barsoux J. L (2003). Managing across culture. London. Pearson publishing. Second edition.

10. Schneider S. C. and Barsoux J. L (2003). Managing across culture. London. Pearson publishing. Second edition.

11. Schuler R. S. and Rogovsky N. (1998). Understanding Compensation Practices Variations Across Firms: The impact of National culture. Journal of International Business studies, Vol. 29, Iss. 1, p. 159-177.

12. Groeschl S. (2003). Cultural implications for the appraisal process. Cross-Cultural Management, Vol. 10, Iss. 1, p. 67.

13. Laurent A. (1983). The cultural diversity of western conceptions of management. International Studies of Management and Organizations, Vol. 13, Iss. 1-2, p.147.

14. Schneider S. C. (1988). National vs. Corporate Culture: Implications for Human Resource Management. Human
Resource Management, Vol. 27, p. 231-246.

15. Kovach R. C. (1995). Matching assumptions to environment in the transfer of management. International studies of Management and Organization, Vol. 24, Iss. 4, p. 83

16. Kobayashi N. (1982). The present and future of Japanese multinational enterprises. International Studies of Man and Organization, Vol. 12, Iss.1, p. 38-58.

17. Ferner A. (1997). Country of origin effects and HRM in multinational companies. Human Resource Management Journal, Vol. 7, Iss. 1, p. 19-37.

18. Fucini J. J. and Fucini S. (1990). Working for the Japanese. New York: The Free Press. In Rosenzweig P. M. and Nohria N. (1994) Influences on human resource management practices in multinational corporations. Journal of International Business Studies, Vol. 25, Iss 2, p. 229.

19. Luptáková S; Vargic B and Kincel I. (2004). National Culture Dimensions and Macro-Indicators. Power Distance in Slovakia. Journal of Economics, Bratislava, Iss. 52, p. 1109-1121. 